\title{
LA SUPRANACIONALIDAD EN LA UNIÓN EUROPEA. COMPARACIÓN CON EL PROCESO CENTRO AMERICANO DE INTEGRACIÓN
}

Por: Abog. Rigoberto Armando Ramos.

Máster en Ciencia Política, Ex-profesor de la Universidad Nacional Autónoma de Honduras.E-Mail: rigobertoarmandoramos@yahoo.com

\section{Resumen}

La figura clave para que exista en Europa una integración real, es la suprana cionalidad: Los países sacrificaron parte de su soberanía para que un órgano regional esté por encima de ellos.- Las decisiones que se adoptan en las instituciones comunitarias (Consejo de la UE y Parlamento Europeo) son obligatorias para todos los Estados miembros.

La supranacionalidad, entendida como renunciar a ciertos aspectos de la soberanía nacional, ha servido de motor de desarrollo para la integración de Europa y no así a la integración de Centroamérica.

Palabras Claves: Supranacionalidad.Unión Europea.- Soberanía Nacional.- Integración Centroamericana.

\section{Abstract}

The key figure for a real integration in Europe is supranationality: the countries sacrificed some of their sovereignty so that a regional institution is over them. Decisions taken in these EU organizations (EU council and European Parliament) are compulsory for all member States.

Supranationality, which means resigning from certain aspects of national sovereignty, has served as a developmental engine for European integration but not for Central America.

Keywords: Supranationalism. - European Union. - National Sovereignty. - Central American Integration. 


\section{INTRODUCCIÓN}

Iniciamos la presentación del tema sobre la supranacionalidad con la afirmación hecha por el Doctor en Derecho, el guatemalteco Rodrigo Montufar al señalar que "El factor que ha permitido la integración política y económica de Europa es la supranacionalidad" (Montufar. 2005)

¿Que entendemos por supranacionalidad? ¿Cuáles son los alcances de este término? ¿Existen distintas categorías de supranacionalidad? ¿Es necesaria la supranacionalidad para la integración?

Estas y muchas interrogantes nos hacemos cuando estudiamos los factores que incidieron en la integración de Europa, desde el inicio con la Comunidad Europea del Carbón y el Acero en 1951, pasando a la Comunidad Europea de la Energía Atómica en 1957, para llegar a el Acta Única Europea de 1986 que habría el camino hacia el mercado único, luego con el tratado de Maastricht que entra en vigor en 1993, que propicia la Unión Europea, cuyo triunfo es la unión monetaria, hasta el Tratado de Ámsterdam que establece la unión política en 1999. (Fontaine. 2006)

La figura clave para que en Europa exista una integración real, es la supranacionalidad: los países sacrificaron parte de su soberanía para que un órgano regional esté por encima de ellos.- Las decisiones que se adoptan en las instituciones comunitarias (Consejo de la UE y Parlamento Europeo) son obligatorias para todos los Estados miembros.

Estudiar la supranacionalidad es incursionar no solo en el campo de la integración, sino adentrarnos en el derecho internacional que puede ser concebido como la forma más universal y a la vez, más específica de organización internacional, y se aplica al igual que todas las leyes únicamente a asuntos específicos.

Como el tema lo establece no basta con conocer la supranacionalidad en la Unión Europea, sino que también tenemos que adentrárnos en el campo centroamericano, haciendo un análisis comparado con el proceso de integración; esto no parece tarea fácil, si tomamos en consideración que lo común en la integración regional centroamericana es la política comercial, aun así su marco de actuación conjunta es continuamente vulnerado por acciones unilaterales.

Unido a lo anterior, la integración centroamericana, sus acuerdos e instituciones, han establecido un marco jurídico e institucional dentro de un marco comunitario, pero sus acciones se desarrollan en un contexto intergubernamental, con una carencia absoluta del concepto de supranacionalidad, afianzando como valores absolutos, la soberanía, la nacionalidad y las fronteras.

Nuestro trabajo sobre la supranacionalidad, tiene como objetivo el de conocer en 
toda su dimensión el concepto de supranacionalidad; Que significa la supranacionalidad para la integración europea; estudiar los avances de la integración centroamericana a fin de comparar en ambos sistemas los alcances de la supranacionalidad.- El presente documento está dividido en cinco acápites para su mejor comprensión: el capítulo primero se refiere al marco teórico de lo que constituye el concepto de supranacionalidad con sus alcances y categorías; un segundo capítulo trata de la supranacionalidad en la Unión Europea; en el capítulo tercero abordamos el caso de la integración centroamericana; en el capítulo cuarto hacemos un análisis comparativo entre la supranacionalidad en la Unión Europea y la integración centroamericana, para culminar con un quinto capítulo de conclusiones.

Nuestra hipótesis general es que la supranacionalidad, entendida como renunciar a ciertos aspectos de la soberanía nacional, ha servido de motor de desarrollo para la integración de Europa y no así a la integración de Centroamérica.

\section{CAPITULO I}

\section{LA SUPRANACIONALIDAD}

Hemos tomado lo relativo a la supranacionalidad del documento de Adolfo Barrera Fuentealba "El funcionalismo y los procesos de integración" (Barrera. 2002 ) por cuanto consideramos que el autor nos proporciona una visión clara y objetiva en lo que consiste en toda su dimensión el concepto de supranacionalidad; declarando en primer lugar que antes de adentrarnos en el concepto de supranacionalidad propiamente tal, es necesario dejar en claro la importancia de establecer previamente una clasificación de la integración en grados.

Considera el tratadista que la integración es un proceso progresivo y dinámico, la creación de organismos comunes está directamente relacionado con la profundización del proceso integrador. Siguiendo esta lógica, en la etapa más superficial de un proceso de integración que corresponde al "área de preferencias arancelarias", no sería necesaria la creación de organismos comunes, ya que sería posible dar cumplimiento a las pautas acordadas con simples oficinas nacionales, que adecuaran coordinadamente las preferencias aduaneras en los estados partes.

En una zona de libre comercio, en general, es conveniente crear órganos comunes de carácter intergubernamental, que tengan funciones meramente coordinadoras de las medidas que deban ir adoptando los Estados partes, para de esta forma lograr el objetivo propuesto. En este periodo, cada Estado sigue conservando todo el poder de decisión sin delegación de facultades. En esta etapa existe un compromiso de los Es- 
tados para reducir de forma progresiva las barreras arancelarias hasta Ilegar a la total desgravación. Un ejemplo del caso descrito es el NAFTA, firmado por Estados Unidos, Canadá y México, mediante el cual se aspira a crear una zona de libre comercio, para lo cual no se han creado órganos de carácter complejo, sino sólo una comisión de comercio y otras comisiones de carácter intergubernamental.

En la etapa de mayor profundidad, denominada "integración económica completa", existe un alto consenso entre los especialistas, respecto a que se deben crear no solo organismos intergubernamentales, sino también supranacionales, debido a que el proceso requiere de la unificación de las políticas de todos los estados miembros, a lo cual, solo es posible Ilegar mediante la creación de entidades que tengan a su cargo el proceso de uniformidad mencionado. Siguiendo esa línea, es absolutamente necesario consolidar instituciones y órganos comunitarios, cuyas decisiones sean obligatorias para los países miembros y sus poblaciones. Es de vital importancia que estos órganos sean de carácter autónomo e independiente, ya que tendrán la misión de coordinar y armonizar las políticas unificadas e impedir el predominio de un Estado sobre otros.

Tomando en cuenta que en la actualidad no existe un proceso de integración que se encuentre en la etapa de "integración completa"propiamente tal, es posible plantearse la necesidad de crear organismos supranacionales en los grados intermedios de la integración, es decir, en la unión aduanera, en el mercado común o en la unión económica.

Para Basaldúa (1996:10), ya en la unión aduanera deben crearse los órganos necesarios, incluidos aquellos competentes para la formación progresiva del derecho comunitario, resultando igualmente indispensable establecer un tribunal de justicia permanente.

La conveniencia y oportunidad de que los órganos de un proceso de integración regional y/o sus capacidades decisorias tengan o no las características de la supranacionalidad, nos conducen a plantearnos cuáles son las implicancias de la palabra "supranacionalidad", tema que trataremos a continuación.

\section{A.- Origen del concepto supranacionalidad}

La palabra "supranacionalidad" tuvo su aplicación concreta cuando se creó la Comunidad Económica del Carbón y del Acero (CECA), por el Tratado de París en 1951. Efectivamente, el Art. 92 punto 2 de dicho Tratado, en la versión francesa, expresamente se refería al neologismo, al mencionar las facultades de la Alta Autoridad, en la forma que sigue: "Los miembros de la Alta Autoridad ejercerán sus funciones, con plena independencia, en interés general de la Comunidad. En el cumplimiento 
de sus deberes, no solicitarán ni atenderán instrucciones de gobierno ni organismo alguno. Se abstendrán de todo acto incompatible con el carácter supranacional de sus funciones. Cada Estado miembro se compromete a respetar este principio y a no intentar influir sobre los miembros de la Alta Autoridad en la ejecución de sus tareas". Posteriormente el Art. 92 del tratado de la CECA fue modificado, eliminándose la expresión "supranacional". Empero, a lo largo de las décadas de integración europea, el proceso se ha ido profundizando y evolucionando en un complejo sistema, que contempla cada vez, más elementos de supranacionalidad. Esto se puede constatar cuando se incursiona en los sucesivos tratados que han ido modelando, desde sus orígenes hasta la actualidad, el proceso de integración de Europa.

\section{B.- Que es la supranacionalidad}

Algunos autores han Ilegado a considerar que, como es difícil determinar un real alcance jurídico de la expresión, se debería renunciar a dar una definición jurídica de la misma, sin embargo, sería posible distinguir dos formas en que se manifiesta el término que se intenta estudiar: 1) La supranacionalidad integral o plena y La supranacionalidad limitada o restringida (Zelada, 1989: 29).

\section{1.- La supranacionalidad plena o integral}

Habitualmente, la idea de la supranacionalidad se identifica con la de los órganos supranacionales, en el convencimiento de que, para que exista supranacionalidad, se requiere que organismos independientes y superiores a los Estados-naciones estén habilitados para dictar normas obligatorias para estos últimos, incluyendo por tanto el concepto, dos aspectos: un órgano comunitario y competencia para expedir decisiones, con aplicabilidad inmediata, sin necesidad de actos de recepción por los Estados partes.

En cambio, los órganos de tipo intergubernamental son aquellos que solo pueden adoptar decisiones que cuenten con la voluntad de los Estados que conforman el tratado de integración como es el caso por ejemplo del NAFTA.

Un órgano, para ser considerado supranacional, debería reunir al menos dos condiciones. La primera, estar integrado de manera que sus miembros no representen a ningún Estado, que se encuentren desvinculados de sus nacionalidades y que respondan nada más que a los intereses comunitarios, sin recibir instrucciones de ningún gobierno. La segunda, tener la potestad de dictar normas obligatorias para los Estados miembros, cuya aplicación sea inmediata y prevalente en los ordenamientos internos de cada uno de ellos.

Aplicación inmediata quiere decir que dicha norma adquiere plena vigencia en los 
Estados partes, sin necesidad de ningún trámite nacional para su "internación". Aplicación prevalente, implica que se debe aplicar con preeminencia a cualquier norma nacional que la contradiga, ya sea de fecha anterior o posterior.

Otros autores consideran que un sistema integracionista es supranacional cuando algunas de las competencias de los Estados son transferidas a determinados organismos comunitarios, delegándose con ello, poderes de decisión de los Estados participantes, para lograr así el cumplimiento de los fines comunitarios junto a los demás Estados miembros.

Según lo indicado,para poder hablar de supranacionalidad,se requiere como elementos de un solo y mismo sistema: objetivos comunes, estructura institucional, competencia y poderes.

Se puede referir a órganos supranacionales, cuando los Estados miembros de una comunidad delegan en organismos independientes de los gobiernos, para que tengan competencia suficiente de normar, ejecutar y dirimir todo lo referente a los fines comunes que tuvieron en miras dichos Estados para integrarse en un espacio común.

Por lo tanto, para que exista supranacionalidad, ese poder comunitario debe ser autónomo, es decir, distinto e independiente de los poderes constituidos de los Estados partes y que las tomas de decisiones que genere se apliquen en forma directa e inmediata en el ámbito geográfico de los países miembros, sin ningún tipo de interferencias.

En síntesis, sobre la base de las apreciaciones acerca de supranacionalidad hasta aquí apuntadas, los elementos que caracterizarían a este tipo serían: la constitución de órganos conformado por miembros de variada nacionalidad; que la designación de éstos fuera un acto del propio organismo, aunque los miembros pudieran ser propuestos por sus países de origen; que su funcionamiento sea independiente y no respondan a instrucciones de los gobiernos partes, siendo esta última, la nota específica de la supranacionalidad, que la diferencia de la intergubernamentalidad y que las tomas de decisiones se incorporen en los ordenamientos jurídicos de los Estados asociados, en forma inmediata, directa y prevalente.

\section{2.- La supranacionalidad limitada o restringida}

Existen otras formas de supranacionalidad, que podrían agruparse, y que hacen más hincapié en la forma de creación e incorporación de las normas, que en la independencia formal de los órganos comunitarios. Para estas posiciones, también nos encontramos con notas, aspectos o situaciones de supranacionalidad.

Cuando un órgano intergubernamental tiene la capacidad de generar normas válidas, con el voto de la mayoría de los miembros, no siendo por tanto necesarios la unani- 
midad ni el consenso, podemos hablar de una supranacionalidad "limitada" orgánica. Por otro lado, cuando las normas que emanan de un órgano intergubernamental tienen la aptitud de penetrar inevitablemente en los ordenamientos jurídicos de los Estados partes en forma inmediata, directa y prevalente, nos encontramos frente a una supranacionalidad "limitada" normativa.

a.- Supranacionalidad "limitada" orgánica: Se manifiesta cuando se dan las siguientes pautas:

1) Un proyecto de unificación como objetivo,

2) La introducción de nuevos principios de representatividad de los Estados, diferentes de la representación tradicional y que conducen a una estructura ción institucional distinta de las organizaciones internacionales, y

3) Un reordenamiento de competencias y poderes a nivel de la soberanía de los Estados.

b.- Supranacionalidad "limitada" normativa: Los órganos intergubernamentales que tienen la potestad de dictar preceptos obligatorios para los Estados partes, caracterizan lo que se denomina una "supranacionalidad atenuada".

Otros autores concuerdan en que el sistema jurídico supranacional se caracteriza por tres elementos: la incorporación inmediata a los ordenamientos nacionales de las normas comunitarias, la primacía sobre los derechos nacionales y el efecto directo sobre los particulares, de modo que la norma pueda ser invocada por ellos ante terceros y accionada ante la justicia.

Cabe realizar ciertos reparos a los tipos de la supranacionalidad "limitada" aquí mencionados. Por un lado, si el órgano intergubernamental pudiera dictar normas por "mayoría", pero que carecieran de las características de efecto inmediato, directo y prevalente para su ingreso en cada Estado, el sistema no sería verdaderamente supranacional, ya que cada Estado mantendría independientemente la Ilave de la aplicabilidad en su orden interno. Por otro lado, si un tratado de integración autorizara que las normas comunitarias ingresaran a los sistemas jurídicos internos de los Estados partes en forma inmediata, directa y prevalente, pero que para su adopción, se requiriera el acuerdo unánime de los socios o el consenso, tampoco habría realmente una situación de supranacionalidad, ya que para que se pudieran sancionar las normas, cada uno de los Estados comprometidos debería dar su visto bueno por medio de sus representantes ante el órgano comunitario intergubernamental, de manera tal, que 
solamente las normas que en conjunto aceptaran los Estados, podrían ser dictadas. En virtud de estas apreciaciones, sobre las especies de la supranacionalidad "limitada", se puede pensar que solo podría haber una forma de supranacionalidad "limitada", la que se daría fusionando en una fórmula las dos vertientes relativas a este tipo (orgánica y normativa)

\section{CAPITULO II}

\section{LA SUPRANACIONALIDAD EN LA INTEGRACION EUROPEA}

Cuando kart w. Deutsch nos habla de la teoría del funcionalismo en su libro sobre "El Análisis de la Relaciones Internacionales" (Deutsch.1994) y nos dice que el funcionalismo de las relaciones internacionales está basada en la esperanza de que se deleguen un número creciente de labores comunes a organizaciones como las $\mathrm{Na}$ ciones Unidas, la Cruz Roja Internacional, la Unión Postal Universal, la Organización Internacional de Aviación Civil, etc., con funciones especificas y que cada una de éstas se convierta con el tiempo en supranacional, es decir, superior a su manifestación, nos está dando un concepto especifico de supranacionalidad, integrado por elementos como ser: labores comunes, funciones especificas, organismos superiores a los países partes, poder y autoridad. Concepto acuñado desde el punto de vista de las relaciones internacionales, por el autor.

En el artículo ¿La integración europea tiene elementos paradigmáticos para la integración en el cono sur? de la Doctora Iris Castejón (Castejón.1991) nos habla sobre la supranacionalidad en la integración europea y nos señala que cada paso de la integración europea ha sido acompañado por instituciones permanentes que gozan de derechos propios, es decir soberanía supranacional; agregando además que esa condición rara vez se ha puesto en duda durante la evolución de la integración y sus instituciones, poniendo como ejemplo el Consejo de Europa, la Comunidad Europea del Carbón y del Acero, así como también en los casos de Euratom, del Grupo de los Seis, el Grupo de los Doce.- En Europa se piensa que no se puede hablar de integración, ni mucho menos practicarla y vivirla, sin transferir una parte de su soberanía nacional a las instituciones integracionistas; se observa este hecho en que el derecho de la comunidad en asuntos sobre la violación de derechos humanos, así como el derecho del Consejo de Europa son superiores al derecho nacional de cada uno de los países miembros, el mismo Tribunal Europeo en la competencia de determinadas materias es superior a los altos tribunales y cortes nacionales; el derecho comunitario europeo supera en dichas materias a los derechos nacionales. 
Los Doctores José J. Romero Rodríguez, Pedro Caldentey del Pozo y Maria Luz Ortega Carpio en su documento: "Siete claves para comprender el proceso de costrucción europea" (Romero y otros. 2001) nos orienta en todo el contenido sobre el principio de supranacionalidad que ha sustentado la integración europea, trataremos de hacer un resumen de sus apreciaciones:

La aventura de la construcción europea no se entiende a partir de ningún determinismo natural, sino que es producto de la voluntad humana. Dos guerras mundiales en treinta años, devastaron a Europa e hicieron surgir la idea de no más guerras; la sensación de un gran fracaso derivado de estos dos acontecimientos bélicos mundiales, determinó la aparición de un sentimiento colectivo de superación de los nacionalismos destructivos.

Todo empezó en 1951 con la CECA, la Comunidad Europea del Carbón y el Acero, con la que los seis países fundadores definieron las bases de lo que sería el Mercado Común, aunque todavía restringido a esas dos producciones estratégicas, productos de gran relevancia durante el conflicto bélico anterior.- A la vez, poco a poco, continuaban las negociaciones para la construcción de un mercado común del uso especifico de la energía atómica, que fructificaron en el EURATOM (o Comunidad Europea de la Energía Atómica) cuyo tratado fundacional se firmó a la vez que el de Roma, en el Palacio del Quirinal, el 25 de marzo de 1957, poniendo en marcha lo que en un principio resultaron ser tres comunidades europeas.

Ese avance en la puesta en común de la soberanía en materia económica dio otro gran salto con el Acta Única Europea (1986) que abría el camino hacia un autentico Mercado Único (con la verdadera libre circulación de mercancías, mediante la abolición de las barreras físicas, desaparecen las aduanas técnicas y fiscales).- No mucho después, el famoso Tratado de Maastricht ( que entra en vigor en 1993 tras un accidentado proceso de ratificación) lanza a la Comunidad Europea por el camino de la "Unión" lo que implica, en el camino ya abierto por el Acta Única, como su principal y más ambicioso proyecto, la implementación de la moneda única, el euro, para 1999.

Tanto el Tratado de Maastricht, con la introducción de sus famosos segundo y tercer pilar (para asuntos de política exterior y de seguridad común y de política interior y de justicia) como el más reciente Tratado de Ámsterdam (que intenta reforzar la ciudadanía europea y hacer del empleo el eje de la Unión) dan la impresión de que rompe con el exclusivismo de la economía y de que se abren campos a la autentica participación política.

Romero Rodríguez, Caldentey del Pozo y Ortega Carpio en su acápite sobre la Supranacionalidad hace referencia a Jean Monnet al señalar: "El futuro de Europa depende 
de la voluntad de organizar una unión de Naciones, en la que cada una debe estar de acuerdo en sacrificar una parte de su independencia económica, política y militar por el bien de la Comunidad en su conjunto" esto en relación a lo que el autor del documento acota, al declarar de que no hay que olvidarlo: la construcción europea se basa esencialmente en la cesión de soberanía.- En su conjunto constituye el concepto de supranacionalidad; esta es una de las ideas que con más energía afirmaron los Ilamados padres de Europa y sus antecesores.- Se trata de una clave absolutamente esencial, sin la cual no se entendería; pone un ejemplo el autor, como es posible que cada vez más competencias vayan siendo trasferidas a los órganos de decisiones comunitarios; sin la cesión de soberanía como principio de acción, no se puede comprender el proceso de ampliación del número de decisiones que se toman en el Consejo de Ministros por mayoría cualificada o ponderada, ni el creciente poder de codecisión del Parlamento.

\section{A.- CESION DE SOBERANIA}

Los tratadistas comentados nos dan ejemplos de cesión de soberanía como los siguientes:

1) Los mecanismos de asignación del número de votos ponderados en el Consejo de Ministros implica un fuerte sesgo a favor de los países pequeños, de modo que las ponderaciones están establecidas de modo que los países pequeños se encuentran sobre representados con relación a su población.- El modelo europeo de cesión de soberanía lleva consigo la imposibilidad de los grandes países de avasallar a los países pequeños.

2) En la misma línea de cesión de soberanía irían los procesos permanentes de que cada vez más decisiones se toman en el Consejo de Ministros por mayoría cualificada y menos por unanimidad y cada vez más la intervención del Parlamento es necesaria, por ser sin duda el órgano más representativo de la voluntad popular, el depositario por excelencia de la legitimidad democrática de la Unión.

3) La política monetaria que instaura la moneda única en la mayor parte de los países de la Unión, representa una cesión de soberanía muy importante.-

La política monetaria única implica el establecimiento de límites muy estrictos a los instrumentos tradicionales de la política económica estatal.-La unión monetaria representa también la cesión de uno de los signos distintivos de la 
soberanía nacional; la emisión de moneda.

Agrega el tratadista que sin embargo, junto con y a pesar de esta dinámica de cesión de soberanía, muchos ven un notable déficit democrático en el funcionamiento de la Unión al grado de que paradójicamente se ha llegado a escribir lo siguiente: "Si la Unión Europea quisiera entrar en la Unión Europea,...no sería admitida, por no reunir los requisitos de contar con una Constitución aprobada democráticamente, no hallarse separados los poderes, no existir un gobierno responsable ante el Parlamento carencia de partidos políticos de ámbito europeo, etc."

Considero de suma importancia lo que el tratadista acota en relación a la juridicidad, pues viene a constituir lo que es la base para el respeto de la institucionalidad y la aplicación de los tratados y convenios dentro del espacio de la supranacionalidad. Pedro Caldentey del Pozo señala que existen tres dimensiones concretas de la juridicidad a saber: los fundamentos jurídicos textuales, la arquitectura institucional y el cumplimiento de lo pactado.

La Comunidad Europea se basa en el derecho, equivale en primer lugar simplemente a reconocer que todos los acuerdos alcanzados han quedado materializados en textos legales (ante todo los tratados, como derecho principal: de Roma; Acta Unica; de Maastricht; o de la Unión Europea; de Ámsterdam) pero también el derecho derivado (reglamentos, directivas, etc., así como la jurisprudencia del Tribunal de Justicia). En principio el aparato jurídico e institucional tiene previsto todos los mecanismos necesarios para la toma de decisiones y su control. Nada queda relegado a la arbitrariedad o a decisiones más o menos caprichosas o extra institucionales.

Para los autores, juridicidad quiere decir, en segundo lugar, que las instituciones puestas en marcha por los Tratados europeos fundadores, funcionan. Es decir que se ha puesto en marcha todo un aparato institucional para la toma de decisiones, basado en una Comisión Europea fuerte como órgano de propuesta y de ejecución, en un Parlamento básicamente consultivo (aunque crecientemente deliberativo), un Consejo de Ministros como legislativo dominante, y un Consejo Europeo (formado por los jefes de gobierno) que es el verdadero motor e impulsor político del proceso. Junto a todos estos órganos que participan en el proceso de decisión, está el Tribunal de Justicia, como institución judicial inapelable, garante del cumplimiento de los Tratados y único intérprete legítimo de los mismos.- La presencia de otros órganos menores (Comité Económico y Social, Comité de las Regiones, Defensor del Pueblo etc.) complica, sin duda, el mapa institucional europeo, aunque su creación ha ido respondiendo, pragmáticamente, a necesidades surgidas en el largo proceso.

En tercer lugar los tratadistas hablan de juridicidad para referirse al hecho de que 
toda la construcción europea, como en principio la de los Estados democráticos que la sustentan, es una construcción "de derecho"; dicho en términos sencillos "lo que se firma se cumple..." Algo que puede parecer elemental, que forma parte de alguna manera de la "cultura" democrática europea más en concreto, de procedencia, hay que decirlo centroeuropea y no precisamente latina o mediterránea y que, sin embargo, está ausente, por ejemplo, de otros proyectos supranacionales.

En todo su contenido el documento de los autores estudiados, lleva implícito el aspecto de la supranacionalidad, aún cuando el tema que trate no se refiera específicamente a supranacionalidad, así vemos como cuando trata sobre el gradualismo de la construcción europea, se refiere también al tema objeto de la presente investigación; y comenta: El gradualismo no es más que la materialización del pragmatismo típicamente europeo. Nada de dogmatismos, ni de maximalismos; se pacta lo posible, se Ilega a consensos sobre los aspectos en que hay acuerdos, y se dejan "aparcados" para mejor ocasión los terrenos de desacuerdo. Nunca se negocia con el principio del "todo o nada". Dado que los avances decisivos han de producirse por unanimidad, lo que en principio podría representar un freno enorme al ritmo de avance de la construcción supranacional, siempre se dan los pasos asumibles por todos y se sigue negociando sobre lo que por ahora no parece maduro.- Al mismo tiempo, una vez que ese pequeño paso se ha dado, ya es prácticamente imposible volver atrás.

Agregan los autores que como suele decir el profesor Juan Velarde que en los avances hacia esta supranacionalidad europea se cumple el lema que aparecía en los estandartes del famoso militar británico Cromwell: "Nulla vestigia retrorsum" que podría traducirse como "Ni un paso atrás." Sus soldados podían avanzar despacio, incluso podían pararse, pero nunca volver sobre sus pasos... si no querían ser castigados por su sanguinario comandante... Algo así,... aunque con menos dosis de violencia, ha ocurrido normalmente en el proceso europeo.

\section{CAPITULO III}

\section{LA INTEGRACION CENTROAMERICANA Y LA SUPRANACIONALIDAD}

Desde nuestra infancia cuando asistíamos a la escuela primaria, nuestros maestros nos hablaban de la unidad centroamericana, del ideal de Francisco Morazán por unir a Centroamérica en una fuerte y hegemónica federación, y es que nos constituimos 
en una de las pocas regiones del mundo que se ha esforzado por más de ciento cincuenta años en alcanzar la integración, especialmente en el campo político; y esto se explica por la historia común de los países que conforman el istmo centroamericano, remontándose, según algunos tratadistas de la materia, al período maya y, posteriormente con la unidad administrativa española que va desde el siglo XVI, hasta inicios del siglo XIX, cabe mencionar también las amenazas externas como la reconquista española, la presencia y expansión inglesa, en Belice, Guatemala, en las Islas de la bahía y la Mosquitia de Honduras y en la costa atlántica de Nicaragua; así como la pretensión de México de homogenizar la zona. Después de la independencia de Centroamérica en 1821 y de la fracasada anexión a México, se conformó el Estado Federal de las Provincias Unidas de Centroamérica de 1823 a 1824, luego con la Constitución decretada el 22 de noviembre de 1824, nace la República Federal Centroamericana (1824-1838).

\section{A.- EVOLUCIÓN HISTORICA}

La Doctora Iris Castejón Pavón en el documento "Nuevos lineamientos del esquema de integración en América Central. Un proceso de renovación" (Castejón. 1993) agrega a lo anterior que desde el inicio de federación se encontró con una marcada división de los partidos políticos que luchaban por la conquista del poder, existiendo dos grandes partidos antagónicos, los conservadores que representaban a los sectores que habían tenido el poder político y económico, y los liberales que impregnados por las ideas del liberalismo político y económico estadounidense y europeo propusieron construir una república nueva que pudiera terminar con los privilegios de la naciente oligarquía y acabar con la hegemonía de Guatemala. A estas disputas se añadieron las diferencias en torno a la forma de organización del Estado, que llevo a cruentas luchas entre los federalistas y los centralistas. Unido a lo anterior, se le suma la cuestión religiosa con respecto al grado de relación que debería mantener el Estado con la Iglesia Católica. Estas diferencias se acentuaron de tal manera que Ilegaron a provocar la ruptura de la Federación en el año de 1838.

Continúa manifestando la autora que otro de los factores que también contribuyó al fracaso de la federación, es que después de la independencia no existían las condiciones adecuadas para una empresa semejante, la herencia de la dominación colonial no favorecía la integración, ya que presentaba un cuadro de inestabilidad política por la ausencia de una autoridad central, los contactos entre las provincias y la Capitanía General de Guatemala giraban en torno al eje de Guatemala y, por otro lado, Nicaragua y Costa Rica estaban bastante aisladas del poder central; en la práctica, no era viable la comunicación por no contar con las vías necesarias. Pese a los in- 
conveientes anteriormente señalados los catorce años de existencia de la República Federal acentuaron la necesidad de construir una sola nación.

Durante los siglos XIX y XX se han intentado numerosos esfuerzos por alcanzar la unidad política centroamericana, habiéndose realizado intentos de unificación, siendo los más relevantes:

a) En 1842-1843 se crea la "Confederación Centroamericana" compuesta por El Salvador, Nicaragua y Honduras, quedando fuera de ella, Guatemala y Costa Rica, ya que ambos gobiernos privilegiaron las tendencias centralistas y rechazaron el convenio de corte federal.

b) En 1885 se intenta desde Guatemala una nueva unificación y sin la aceptación de Nicaragua y Costa Rica se proclama la "Unión Centroamericana".

c) En 1895 se lleva a cabo otro nuevo intento cuando Nicaragua, Honduras, El Salvador, y posteriormente Guatemala forman la "República Mayor de Centroamérica"; al emitir la constitución en 1898 se le cambió el nombre por el de "Estados Unidos de Centroamérica".

d) El último esfuerzo unionista se intentó con motivo del centenario de la proclama de independencia.En el mes de enero de 1921 se proclamó la Constitución de la "República de Centroamérica con la participación de Guatemala, Honduras, El Salvador y Costa Rica que duró hasta enero de 1922, en este intento Nicaragua no participó, debilitando fuertemente la tentativa.

Como podemos apreciar, en estos intentos de integración nunca han estado presentes los cinco países centroamericanos, condición indispensable para llevar a formar la unión, es más podemos apreciar que no ha existido un ápice de cesión de soberanía por parte de uno u otro estado, más bien se instituye como una forma de integración el hecho de conservar la propia identidad de cada uno de los estados, tal y como podemos apreciar en la Constitución de 1921 en donde en sus primeros Artículos determinan el grado de integración a saber:

Artículo 1.- Los Estados de Guatemala, El Salvador y Honduras, en unión perpetua e indisoluble constituyen una Federación soberana e independiente que se denomina REPÚBLICA DE CENTROAMERICA. 
Artículo 2.- La nación reconoce que, por razones étnicas, geográfica e históricas también deben integrarla los Estados de Nicaragua y Costa Rica. Por consiguiente, la Federación seguirá considerándolos como parte integrante de la familia centroamericana.

Artículo 3.- La soberanía es inalienable e imprescriptible y reside en la nación. En el Artículo 5 se ponía a Tegucigalpa como la capital de la República.

Evidencia claramente el hecho del nacionalismo estatal, el haber durado esta constitución solamente un año, y no aceptar como capital de la República a Tegucigalpa, así como el de remarcar el principio de soberanía, contrario a lo señalaba el Tratado de Paris de 1951, claro, las situaciones y condiciones son diametralmente opuestas. Se palpa que no está presente hasta el año de 1921 el concepto de supranacionalidad.

La Doctora Castejón nos sigue orientando en cuanto al avance integracionista de Centroamérica en los años cincuenta y setenta del siglo pasado, de la siguiente manera: Una nueva dimensión surge en los años cincuenta en lo económico y lo político en el esfuerzo de integración, el punto de partida en el campo económico lo constituyó el diagnóstico elaborado por la Comisión Económica para América Latina (CEPAL), que consideró que Centroamérica no podía salir del subdesarrollo con una economía de monocultivo exportadora con vínculos económicos establecidos hacia fuera, vía comercio exterior, esto hace que la demanda se origine en el exterior acentuando cada vez más las condiciones de dependencia y de retraso tecnológico, industrial e institucional. La CEPAL (Comisión Económica para América Latina y el Caribe) recomendó impulsar la integración mediante la industrialización a través del modelo de sustitución de importaciones para lograr el desarrollo hacia adentro dirigido a satisfacer el mercado interno.

En el mes de febrero de 1960, los gobiernos de Guatemala, Honduras y El Salvador firmaron el Tratado de Asociación Económica

El 13 de diciembre de 1960 Honduras, Guatemala, El Salvador y Nicaragua suscribieron el Tratado General de Integración Económica de Centroamérica", base del Mercado Común Centroamericano, Costa Rica suscribió el Tratado en noviembre de 1962.

El Tratado General contempla dos elementos fundamentales de la integración: el régimen de industrias y el libre comercio. En cuanto a los aspectos institucionales del mismo, se creó el Consejo Económico como instancia superior, conformado por los ministros de economía; el Consejo Ejecutivo a nivel técnico; la Secretaria permanente 
(SIECA) encargada de coordinar, dirigir e implementar los acuerdos de integración y se constituyó el Banco Centroamericano de Integración Económica (BCIE), como instrumento financiero.

Podríamos establecer algún grado muy leve de las características de la supranacionalidad en el establecimiento de los organismos antes señalados, pero la verdadera identificación del concepto estaría en la emisión de resoluciones y su cumplimiento por los estados miembros.

En el campo político nos señala la tratadista de que los efectos de la segunda guerra mundial despertó en los centroamericanos el viejo y romántico sueño unionista, lo cual se vio favorecido por los movimientos integracionistas latinoamericanos y por el ambiente pacifista internacional que había creado la Conferencia de San Francisco de 1945. La carta de San Francisco dio origen a la Organización de las Naciones Unidas, creando y fortaleciendo acuerdos y organismos regionales cuyo fin fuera el de atender asuntos relativos al mantenimiento de la paz y la seguridad internacional. La convergencia de estos factores posibilitó en 1951 la creación de la Organización de Estados Centroamericanos (ODECA), cuyas principales funciones eran las de buscar soluciones conjuntas a los problemas comunes, promover el desarrollo económico, social y cultural mediante la acción cooperativa y solidaria e impulsar y coordinar el proceso de integración.

En los años setenta al poner en práctica las recomendaciones de la CEPAL se observa un cambio positivo en la industrialización, modernización en el agro, desarrollo en algunos sectores sociales, pero no se establecieron cambios en el sistema político; la democracia en Centroamérica no podía surgir de la bonanza económica y surgen a finales de los años setenta y principios de los ochenta el paso de las dictaduras oligárquicas militares al proceso de democratización en los países de Guatemala, El Salvador y Honduras, pero aún así la influencia de los gobiernos militares debilitaron el consenso político que se requería para el buen funcionamiento de la integración. Otro problema que mino el proceso de integración fue el hecho de que más que un proceso de integración, fue buscar el perfeccionamiento de una zona de libre comercio con miras a crear la unión aduanera; unido a la desproporción en el desarrollo industrial de los países que trajo como consecuencia que el comercio intrazonal no beneficiara a todos por igual, siendo motivo de fuertes controversia especialmente de Honduras y Nicaragua, que tenían un menor desarrollo industrial.

Otro factor de la contramarcha en los años setenta, fue la disparidad entre el bajo poder adquisitivo de la gran mayoría del mercado y la oferta excesiva de productos manufacturados, superando la producción al consumo en casi todos los sectores; culminando con la guerra del fútbol entre Honduras y El Salvador en 1969 estancando 
la integración centroamericana.

El Mercado Común se desenvolvió con grandes dificultades en los años setenta y ochenta, sin llegar a paralizarse, pese a los obstáculos originados por el conflicto de poder; los países centroamericanos concurrieron unificados como una región ante la Comunidad Europea para suscribir el Acuerdo de Luxemburgo en 1985, mediante el cual la Comunidad Europea (CE) otorgó cooperación a los países de Centroamérica y Panamá como bloque.

En 1987 se firma el Tratado Constitutivo del Parlamento Centroamericano; en el campo económico, se logró en 1985 concretar un nuevo arancel uniforme para la importación, y en 1990 se inició un nuevo Sistema de Pagos Centroamericanos. En este período se hicieron esfuerzos parcialmente exitosos para que no se interrumpiera el comercio intrazonal, tratando de mantener las formas multilaterales frente a la fuerte tendencia del comercio bilateral. Así mismo las instituciones del sistema de integración siguieron funcionando. El proceso de integración de esos años experimentó un "progreso silencioso" que no solo lo salvo del fracaso total, sino que le dio las bases que han servido para su relanzamiento.

En busca de los objetivos de la reactivación de la integración fijados en la VIII Cumbre Presidencial de Antigua, hacia una zona de libre comercio entre los países centroamericanos, como primer paso del renovado esquema, los países centroamericanos han estado marchando a ritmos y tiempos diferentes. Honduras y Guatemala se adelantaron con la suscripción de un acuerdo bilateral de libre comercio, en abril de 1992. La idea fundamental de este convenio es acelerar la firma de tratados similares con El Salvador. De ahí presionar a los demás países centroamericanos a sumarse a este nuevo intento integracionista. En el mes de mayo de 1992 Guatemala, Honduras y El Salvador deciden conformar el "triangulo norte" a través de un acuerdo trilateral para crear una zona de libre comercio y una unión aduanera que ha sido puesta en práctica en forma experimental.

En cuanto a los adelantos obtenidos en relación a la Supranacionalidad en este periodo, la Doctora Castejón nos refiere que es por medio del PARLACEN que se percibe una corriente de iniciativa a tratar asuntos referentes a la supranacionalidad, así en la reunión de trabajo celebrada en Tegucigalpa, el 22 de abril de 1993, la discusión se centró en temas tan sensibles como los relativos a la supranacionalidad. En esa reunión se consideró la necesidad de la adopción de una ciudadanía centroamericana, y de trabajar en un estudio sobre un estatuto marco para una futura Constitución general de la región. También se pretende homogenizar la legislación laboral en la región; es obvio que los diputados cuentan con buena disposición de trabajo, pero según la autora no se puede hablar tan temprano de temas como la supranacionalidad que en 
otros esquemas de integración del mundo, siguen siendo motivo de interminables discusiones.

En 1993 se suscribió el Protocolo de Guatemala, que reforma el Tratado General de Integración Económica (TGIE), impregnando con ello un nuevo dinamismo a la integración económica. Sin embargo, cabe aclarar que actualmente sólo cinco de los países miembros del SICA participan del Mercado Común Centroamericano (MCCA). Estos países decidieron al inicio del siglo XXI, avanzar de la concepción de MCCA que habían venido desarrollando, hacia una Unión Aduanera, con el objetivo de profundizar el proceso de integración económica. Actualmente se está negociando el establecimiento de ésta.

Consideramos importante para conocer el alcance de la supranacionalidad en la región hacer referencia a los organismos y a la institucionalidad de la integración, por cuánto nos dirán que grado en que estos tienen competencia para tomar decisiones y aplicar las mismas en los Estados parte.

\section{B.- INSTITUCIONALIDAD REGIONAL}

Agregan los tratadistas antes mencionados que Centroamérica cuenta con una vasta institucionalidad regional, sin embargo, no todos los países son estados miembros activos de ella, ni tampoco es una institucionalidad a la cual se le han trasladado mayores competencias por parte de los Estados.

Hay además dificultades en el desarrollo institucional que provienen principalmente de los objetivos, los medios y la relación que cada ente posee en el contexto institucional en que se ubica. Con ello, por ejemplo, las diversas secretarías básicamente brindan apoyo a los Consejos de Ministros, sin llegar a convertirse en órganos ejecutivos de la integración.

La Secretaria de Integración Económica Centroamericana (SIECA) ha sido un eje en el que los gobiernos se apoyan para las negociaciones de la integración económica intrarregional, pero no le han trasladado competencias nacionales. En las negociaciones con terceros países ha tenido un papel poco relevante por decisión de los gobiernos; nunca se le ha autorizado para que sea vocero o negociador de los estados frente a terceros. La funciones de la SIECA se centran en realizar trabajos y estudios que los órganos del subsistema de la integración económica o el Consejo de Ministros de Economía de Centroamérica (Comieco) le encomiendan y si bien tiene capacidad para proponer, sus propuestas no son vinculantes por lo que pueden sustituirse por otras que planteen los Estados miembros.

El Parlamento Centroamericano (PARLACEN) tiene entre sus principales funciones la de servir de foro deliberativo en el análisis de asuntos comunes en lo político, 
económico, social cultural y de seguridad de la región centroamericana; esto con el objetivo de impulsar los procesos de integración y cooperación entre los Estados miembros. También se le establece como función la elaboración de propuestas de tratados y convenios a negociar entre los Estados miembros, el fortaleciendo del derecho internacional y la formulación de recomendaciones a los Estados con relación a los asuntos de su competencia.

Sin embargo, el carácter "declarativo" y la carencia de iniciativas legislativas dentro del SICA, más las críticas por su representatividad en cuanto a cómo y quienes son electos en los países para el PARLACEN, ha planteado la necesidad de hacer reformas importantes al mismo.

La Corte Centroamericana de Justicia cuenta entre sus funciones el de garantizar el respeto al derecho, tanto en la interpretación como en la ejecución del Protocolo de Tegucigalpa y sus instrumentos o actos derivados del mismo. El Estatuto de la Corte ha sido ratificado sólo por El Salvador, Honduras y Nicaragua.

La situación de la Corte Centroamericana de Justicia es delicada debido a la necesidad de contar con un mecanismo jurídico adecuado que le de fuerza a la normatividad comunitaria. La Corte no puede actuar como un instrumento de garantía al orden jurídico comunitario, por su misma debilidad, la integración económica estableció su propio mecanismo de solución de controversias entre los Estados.

Relacionado con la supranacionalidad considero necesario incorporar al presente acápite lo relacionado con la identidad centroamericana y los autores del documento estudiado, establecen que el proceso de integración centroamericana no está sustentado por la presencia de una identidad centroamericana; en parte porque no se han concretado esfuerzos interinstitucionales de alto impacto, articulados y sostenibles para desarrollar dicha identidad. Tampoco se ha invertido en acciones que promuevan un sentido de pertenencia a la región por parte de la ciudadanía: pareciera que los beneficios de la integración para el bienestar de los centroamericanos son poco claros, lo que no ayuda a generar ese sentido de pertenencia.

\section{CAPITULO IV}

\section{ANALISIS COMPARATIVO ENTRE LA SUPRANACIONALIDAD DE LA UNION EUROPEA Y LA INTEGRACION CENTROAMERICANA}

Habiendo establecido en los acápites anteriores las formas en que la supranacionalidad es tomada en consideración en el desarrollo de la integración europea y la integración de Centroamérica, pasamos en esta oportunidad a establecer las diferencias 
o similitudes que podrían existir entre ambos sistemas:

1.- Como ha quedado establecido, la construcción europea se basa esencialmente en la cesión de soberanía.

En la integración centroamericana no se ha tomado en consideración este aspecto al grado que, en ningún documento se habla al respecto sobre cesión de soberanía ni sobre supranacionalidad, platicas intrascendentes se llevaron a cabo en el año de 1992, en el PARLACEN que no han Ilegado a fructificar.

2.- En el caso de la integración europea, la Comisión es el órgano ejecutivo, con capacidad de propuesta y de ejecución y actúa como guardián de los tratados, lo que le permite demandar a los Estados ante el Tribunal Europeo, si considera que estos violan la normativa comunitaria.

La SIECA solamente actúa como una secretaría del Consejo de Ministros, no le han trasladado competencias nacionales.

3.- EI PARLACEN no ha logrado reproducir los aspectos positivos del Parlamento Europeo, órgano en el que se inspiró su creación y con el que se compara.- Al Parlamento Europeo se le han ido aumentando sus poderes y se ha establecido como colegislador para ciertos temas, posee poderes presupuestarios y ejerce un control democrático sobre diferentes instancias europeas. Por el contrario al PARLACEN se le ha criticado por el elevado costo financiero que le cuesta a los estados comparado con el bajo desempeño de sus funciones, que hasta la fecha no han emitido ni siquiera una declaración de proyectos de beneficio para la sociedad centroamericana.

4.- La Corte Centroamericana de Justicia a diferencia del Tribunal Europeo no puede actuar como un instrumento de garantía al orden jurídico comunitario.

5.- La integración política del Sistema de Integración Centroamericano, existe en una forma centrada en la coordinación y la cooperación entre los Estados, y aunque exista una institucionalidad y un marco jurídico, lo cierto es que el acatamiento de la gran mayoría de las decisiones dependen más de la voluntad política de los gobiernos de turno, ya que no hay mecanismos para

1 Explicación tomada del Documento de Trabajo “La Integración Centroamericana: Hacia una relación virtuosa entre cohesión social y desarrollo económico de Doris Osterlof Obregón y Jorge Nowalski Rowinski. (Osterlof y otro. 2006) 
obligar a los países al cumplimiento de los acuerdos tomados.

En cambio en la Unión Europea los Estados miembros basan su proceso en un compromiso de trabajar juntos en pro de la paz y la prosperidad, pero sin intentar construir un Estado que sustituya a los actuales, ni tampoco establecer una simple organización internacional. Se han creado instituciones comunes en las que los Estados delegan parte de su soberanía, con el fin de que se puedan tomar decisiones democráticamente y a escala europea, sobre asuntos específicos de interés común.

\section{CONCLUSIONES}

Las conclusiones que presento a continuación prueban la hipótesis planteada en el párrafo de presentación del tema, en el sentido de que la supranacionalidad entendida como el hecho de renunciar a ciertos aspectos de la soberanía nacional ha sido motor de desarrollo para la integración europea, no así para la integración de Centroamérica.

- La integración de Europa, desde sus inicios incorporó en el Artículo 92, punto 2 del Tratado de Paris el principio de supranacionalidad, aún cuando con posterioridad en los siguientes tratados no se menciona en forma expresa, pero si tácitamente se encuentra en ellos.

- En el sistema de integración centroamericana en ningún momento, ni en forma expresa o tacita se hace referencia a la supranacionalidad.

- La Integración de Europa, si bien nació como una comunidad económica, su fin ulterior y posterior fue el de crear las condiciones para el establecimiento de una paz duradera. En el presente siglo XXI la misión de Europa es la de ofrecer paz, prosperidad y estabilidad a sus ciudadanos; superar las divisiones en el continente europeo; velar porque sus ciudadanos puedan vivir con seguridad; promover el desarrollo económico y social equilibrado; hacer frente a los retos de la globalización y preservar la diversidad de los pueblos de Europa; defender los valores compartidos por los europeos, como el desarrollo sostenible y el cuidado del medio ambiente, el respeto de los derechos humanos y la economía de mercado social (Fontaine.2006).

- En cambio la integración centroamericana desde la década de los años sesenta, inició su proceso de integración en el campo económico intraregional, por recomendaciones de la CEPAL a fin de buscar el desarrollo de Centroamérica mediante la sustitución de importaciones, la industrialización y modernización 
en el agro. No fuimos nosotros quienes promovimos la integración, sino que fue casi impuesta desde afuera; por tanto la comunidad centroamericana no cuenta con una conciencia clara y definida de los beneficios de la integración, manteniendo permanentemente los arraigados principios de soberanía, nacionalismo y fronteras.

- En Centroamérica no hemos superado los problemas fronterizos con los países vecinos; Costa Rica tiene problemas con Nicaragua en la línea divisoria del rió San Juan; Honduras disputa con Nicaragua el mar territorial en el paralelo 15 y en la bocana del Golfo de Fonseca; asimismo Honduras continua con los problemas limítrofes marítimos en el Pacifico con El Salvador, disputando la posesión de la isla de Conejo y la salida de Honduras a mar abierto. Situaciones como estas ponen en precario la integración, reflejando en toda su plenitud los principios de Soberanía Nacional y defensa de sus fronteras. En Europa se superaron problemas similares a fin de mantener la seguridad y la paz del continente.

- En la agenda de la Unión Europea la cohesión social aparece definida como un objetivo de la agenda de política social, los Jefes de Estado y de Gobierno Europeo, se comprometieron hacer su economía, basada en el conocimiento, la más dinámica y competitiva en el mundo, capaz de un crecimiento económico sostenible con más y mejores empleos y con una mayor cohesión social, dentro del respeto del medio ambiente. En cambio en Centroamérica la necesidad de cohesionar la sociedad pasa a un plano más amplio aumentando los desafíos, ya que no se trata sólo de las personas que conviven en un espacio geográfico del país, sino que también se debe establecer niveles de conocimiento, respeto tolerancia, participación activa, de tal manera que se legitimen las acciones integracionistas de los Estados.

\section{BIBLIOGRAFIA}

Adolfo Barrera Fuentealba.- El Funcionalismo y los Procesos de Integración.- www. monografias.com. 2007

Doris Osterlof Obregón y Jorge Nowalski Rowinski. La Integración Centroamericana: Hacia una relación virtuosa entre cohesión social y desarrollo económico. Documento de trabajo, Centro Internacional para el Desarrollo Humano, CIDH. San José, Costa Rica.2009 
Iris Castejón, Manfred Mols. ¿La Integración Europea tiene elementos paradigmáticos para la integración en el cono sur?, en: Revista Perspectiva Internacional Paraguaya, Año III, No.5 (Enero-Junio de 1991) Págs. 89-101.

Iris Castejón Pavón. Nuevos Lineamientos de Integración en América Central. Un proceso de renovación, en: Hans - Joachim Lauth und Manfred Mols. Integration und Koo 'peration auf dem amerikanischen Konti-nent. Lateinamerikanische Perspektiven in den neunziger Jahren. Mainz 1993. págs. 119 - 142.

José J. Romero Rodríguez, Pedro Caldentey del Pozo y Maria Ortega Carpio.- Siete Claves para Comprender el Proceso de Construcción Europea. Lectura No. 1 Taller Integración y Cooperación Económica. POS-CAE. UNAH. Tegucigalpa, MDC. 2001.

Kart W. Deutsch.- El Análisis de las Relaciones Internacionales. Ed. Gernika, 3ra Edición. México, 1994. Pág. 285 - 303.

Pascal Fontaine.- Doce Lecciones sobre Europa.- Comisión Europea.- http://europa. eu/abc/12lessons/index_es.htm. Año 2007

Rodrigo Montufar.- Nacionalidad es Exito de UE.- Prensa Libre.com.- Guatemala, lunes 9 de mayo de 2005. 